\title{
FGFR-TKI resistance in cancer: current status and perspectives
}

\author{
Sitong Yue ${ }^{1 \dagger}$, Yukun $\mathrm{Li}^{2+}$, Xiaojuan Chen ${ }^{1}$, Juan Wang ${ }^{2}$, Meixiang $\mathrm{Li}^{2}$, Yongheng Chen ${ }^{1,3^{*}}$ and Daichao Wu $\mathrm{U}^{1,2,3,4^{*}}$ (D)
}

\begin{abstract}
Fibroblast growth factor receptors (FGFRs) play key roles in promoting the proliferation, differentiation, and migration of cancer cell. Inactivation of FGFRs by tyrosine kinase inhibitors (TKI) has achieved great success in tumor-targeted therapy. However, resistance to FGFR-TKI has become a concern. Here, we review the mechanisms of FGFR-TKI resistance in cancer, including gatekeeper mutations, alternative signaling pathway activation, lysosome-mediated TKI sequestration, and gene fusion. In addition, we summarize strategies to overcome resistance, including developing covalent inhibitors, developing dual-target inhibitors, adopting combination therapy, and targeting lysosomes, which will facilitate the transition to precision medicine and individualized treatment.
\end{abstract}

Keywords: FGFR, Tyrosine kinase inhibitor, Drug resistance, Gatekeeper mutation, Lysosome sequestration

\section{Background}

Fibroblast growth factor receptors (FGFRs), a subfamily of receptor tyrosine kinases (RTKs), consist of five members (FGFR1-5) that share remarkable sequence homology [1]. They typically contain the extracellular domain, hydrophobic transmembrane domain, and intracellular tyrosine kinase domain $[2,3]$. Unlike the other four members, FGFR5 (known as FGFRL1) lacks a tyrosine kinase domain. It plays a role in regulating excessive activation of the FGF-FGFR1 signaling pathway $[4,5]$. The signaling axis of FGFRs is primarily activated in a liganddependent manner, by binding of fibroblast growth factors (FGFs) and the subsequent receptor dimerization induced intracellular kinase transautophosphorylation events [6]. Meanwhile, FGFRs can also be activated in a ligand-independent manner, such as chromosome

\footnotetext{
*Correspondence: yonghenc@163.com; wudc_lab@163.com; wudc@umd. edu

†Sitong Yue and Yukun Li have contributed equally to this paper ${ }^{1}$ Department of Oncology, Laboratory of Structural Biology, NHC Key Laboratory of Cancer Proteomics, State Local Joint Engineering Laboratory for Anticancer Drugs, Xiangya Hospital, Central South University, Changsha 410008, Hunan, China

Full list of author information is available at the end of the article
}

translocation induced FGFRs gene fusion with other constitutively expressed genes [7].

The FGF/FGFR signaling pathway is closely related to the occurrence of embryogenesis, angiogenesis, tissue homeostasis, and wound repair [8]. It also plays critical roles in cell proliferation, differentiation, apoptosis, and migration $[9,10]$. Aberrantly activated FGF/FGFR signaling axis leads to a variety of diseases, especially malignant tumors, which are caused by gene amplification, mutation, and gene fusion $[11,12]$.

Blocking the FGF/FGFR signaling axis by tyrosine kinase inhibitors (TKIs) was proved to be a successful therapeutic strategy in numerous tumor types [13]. Erdafitinib was the first approved FGFR-TKI for treating metastatic urothelial carcinoma based on remarkable results of the phase II trial (Table 1, NCT02355597) $[14,15]$. And a further phase III trial (NCT03390504) is being performed to compare the efficacy of Erdafitinib versus Vinflunine or Docetaxel or Pembrolizumab in advanced urothelial cancer. Multiple clinical trials are being conducted on the effectiveness of Erdafitinib in a variety of cancers, such as nonsmall cell lung cancer (NCT03827850), advanced solid tumor (NCT02465060, NCT03155620, NCT03120714, 
Table 1 Clinical development of FGFR-TKIs

\begin{tabular}{|c|c|c|c|c|}
\hline Drugs & Company & Targets & Approved/clinical trials & Patients and clinical results \\
\hline \multirow[t]{2}{*}{ Erdafitinib (JNJ-42756493) } & \multirow[t]{2}{*}{ Janssen } & \multirow[t]{2}{*}{ Pan-FGFR } & $\begin{array}{l}\text { FDA approved } \\
\text { Phase II } \\
\text { NCT02365597 }\end{array}$ & $\begin{array}{l}\text { Advanced or Metastatic urothelial carcinoma with FGFR2/ } \\
\text { FGFR3 genetic alterations and had a history of disease } \\
\text { progression within } 12 \text { months of neoadjuvant or adju- } \\
\text { vant platinum-containing chemotherapy. Results: ORR: } \\
\text { 40\%; median PFS: } 5.5 \text { months; median OS: } 13.8 \text { months }\end{array}$ \\
\hline & & & $\begin{array}{l}\text { Phase I/lla } \\
\text { NCT02421185 }\end{array}$ & $\begin{array}{l}\text { Advanced hepatocellular carcinoma with FGF19 amplifi- } \\
\text { cation. Results: ORR: 4.8\%; DCR: } 35.7 \% \text { VS 9.1\%; median } \\
\text { PFS: } 1.58 \text { months VS } 1.31 \text { months (FGF19 amplification } \\
\text { VS no-FGF19 amplification) }\end{array}$ \\
\hline Pemigatinib (INCB054828) & Incyte & Pan-FGFR & $\begin{array}{l}\text { FDA approved } \\
\text { Phase II } \\
\text { NCT02924376 }\end{array}$ & $\begin{array}{l}\text { Documented disease progression following at least one } \\
\text { previous systemic cancer therapy, locally advanced } \\
\text { or metastatic cholangiocarcinoma with FGFR2 gene } \\
\text { fusion or rearrangement. Results: ORR: } 35.5 \% \text {; median } \\
\text { PFS: } 6.9 \text { months; median OS: } 21.1 \text { months; median DOR: } \\
7.5 \text { months; DCR: } 82.0 \%\end{array}$ \\
\hline Futibatinib (TAS-120) & Taiho Pharm & Pan-FGFR & Phase II NCT02052778 & $\begin{array}{l}\text { Disease progression after } \geq 1 \text { line of systemic therapy } \\
\text { (gemcitabine plus platinum-based chemotherapy), } \\
\text { advanced or metastatic unresectable intrahepatic } \\
\text { cholangiocarcinoma with FGFR2 gene fusions or other } \\
\text { rearrangements. Results: ORR: } 34.3 \% \text {; DCR: 76.1\%; } \\
\text { median DOR: } 6.2 \text { months }\end{array}$ \\
\hline CH5183284 (Debio-1347) & Debio & FGFR1/2/3 & $\begin{array}{l}\text { Phase II } \\
\text { NCT03834220 }\end{array}$ & $\begin{array}{l}\text { Solid tumors harboring FGFR } 1 / 2 / 3 \text { gene fusion or rear- } \\
\text { rangement }\end{array}$ \\
\hline ASP5878 & Astellas & Pan-FGFR & $\begin{array}{l}\text { Phase I } \\
\text { NCT02038673 }\end{array}$ & $\begin{array}{l}\text { Urothelial carcinoma, hepatocellular carcinoma, or } \\
\text { squamous cell lung carcinoma with FGFRs genetic } \\
\text { alterations }\end{array}$ \\
\hline \multirow[t]{2}{*}{ Dovitinib (TKI258) } & \multirow[t]{2}{*}{ Novartis } & \multirow[t]{2}{*}{ FGFR1/2/3; KIT; VEGFR } & $\begin{array}{l}\text { Phase II } \\
\text { NCT01861197 }\end{array}$ & $\begin{array}{l}\text { Advanced squamous non-small cell lung cancer with } \\
\text { FGFR1 amplification. Results: ORR: 11.5\%; DCR: 50\%; } \\
\text { median PFS: } 2.9 \text { months; median OS: } 5.0 \text { months }\end{array}$ \\
\hline & & & $\begin{array}{l}\text { Phase II } \\
\text { NCT01379534 }\end{array}$ & $\begin{array}{l}\text { FGFR2 mutated or WT advanced and/or metastatic endo- } \\
\text { metrial cancer. Results: ORR: } 4.5 \% \text { VS 16.5\%; DCR: } 63.6 \% \\
\text { VS 51.6\%; PFS: } 4.1 \text { months VS } 2.7 \text { months; 18-week } \\
\text { PFS rate: } 31.8 \% \text { VS 29\%; median OS: } 20.2 \text { months VS } \\
\text { 9.3 months (FGFR2 mutation VS FGFR2 WT) }\end{array}$ \\
\hline PRN1371 & Principia & Pan-FGFR & $\begin{array}{l}\text { Phase I } \\
\text { NCT02608125 }\end{array}$ & $\begin{array}{l}\text { Metastatic urothelial carcinoma with FGFRs genetic } \\
\text { alterations }\end{array}$ \\
\hline LY2874455 & Eli-Lilly & Pan-FGFR; VEGFR2 & $\begin{array}{l}\text { Phase I } \\
\text { NCT01212107 }\end{array}$ & Advanced solid-organ cancer \\
\hline \multirow[t]{2}{*}{ Infigratinib (BGJ398) } & \multirow[t]{2}{*}{ Novartis } & \multirow[t]{2}{*}{ Pan-FGFR } & $\begin{array}{l}\text { Phase II } \\
\text { NCT02150967 }\end{array}$ & $\begin{array}{l}\text { Advanced or metastatic cholangiocarcinoma with FGFRs } \\
\text { alterations whose disease progressed despite prior sys- } \\
\text { temic therapy. Results: ORR: 14.8\%; DCR: 75.4\%; median } \\
\text { PFS: } 5.8 \text { months }\end{array}$ \\
\hline & & & $\begin{array}{l}\text { Phase II } \\
\text { NCT02160041 }\end{array}$ & $\begin{array}{l}\text { Solid tumor and hematologic malignancies with FGFRs } \\
\text { genetic alterations. Results: CBR: 15\%; ORR: 7.5\%; } \\
\text { median PFS: } 1.8 \text { months; OS: } 6.2 \text { months }\end{array}$ \\
\hline AZD4547 & AstraZeneca & Pan-FGFR & $\begin{array}{l}\text { Phase II } \\
\text { NCT02465060 }\end{array}$ & $\begin{array}{l}\text { Advanced refractory solid tumors, lymphomas, or } \\
\text { multiple myeloma with FGFR1/2/3 aberrations. Results: } \\
\text { Median PFS: } 3.4 \text { months, 6-month PFS rate: 15\%; (For } \\
\text { FGFR fusions patients, ORR: 22\%, 6-month PFS: 56\%) }\end{array}$ \\
\hline Derazantinib (ARQ-087) & Basilea & $\begin{array}{l}\text { Pan-FGFR; RET; DDR2; } \\
\text { KIT;VEGFR; PDGFRß }\end{array}$ & $\begin{array}{l}\text { Phase } 1 / \| \\
\text { NCT01752920 }\end{array}$ & $\begin{array}{l}\text { Advanced, inoperable, or metastatic solid tumors with } \\
\text { FGFRs genetic alterations who failed to respond to } \\
\text { standard therapy or for whom standard curative } \\
\text { therapy does not exist. Results: ORR: } 20.7 \% \text {; DCR: } 82.8 \% \text {; } \\
\text { median PFS: } 5.7 \text { months }\end{array}$ \\
\hline E7090 & Eisai & FGFR1/2/3 & $\begin{array}{l}\text { Phase II } \\
\text { NCT04238715 }\end{array}$ & $\begin{array}{l}\text { Unresectable advanced or metastatic cholangiocarci- } \\
\text { noma with FGFR2 gene fusions }\end{array}$ \\
\hline HMPL-453 & Chi-Med & FGFR1/2/3 & $\begin{array}{l}\text { Phase II } \\
\text { NCT04353375 }\end{array}$ & Advanced bile duct cancer with FGFR2 fusions \\
\hline Rogaratinib (BAY-1163877) & Bayer & Pan-FGFR & $\begin{array}{l}\text { Phase III } \\
\text { NCT03410693 }\end{array}$ & $\begin{array}{l}\text { Advanced or metastatic urothelial carcinoma with } \\
\text { FGFR-positive after receiving prior platinum-containing } \\
\text { chemotherapy (Rogaratinib VS chemotherapy) }\end{array}$ \\
\hline
\end{tabular}


Table 1 (continued)

\begin{tabular}{|c|c|c|c|c|}
\hline Drugs & Company & Targets & Approved/clinical trials & Patients and clinical results \\
\hline Roblitinib (FGF401) & Novartis & FGFR4 & $\begin{array}{l}\text { Phase } 1 / 11 \\
\text { NCT02325739 }\end{array}$ & FGF19-driven hepatocellular cancer \\
\hline ODM-203 & Orion & FGFR;VEGFR1/2/3 & $\begin{array}{l}\text { Phase I/lla } \\
\text { NCT02264418 }\end{array}$ & $\begin{array}{l}\text { Advanced or metastatic solid tumors for which treatment } \\
\text { according to the guidelines was no longer available. } \\
\text { Results: ORR: 9.2\%; median PFS: } 16.1 \text { and } 12.4 \text { weeks for } \\
\text { aberrant or non-aberrant FGFR }\end{array}$ \\
\hline ICP-192 & InnoCare & Pan-FGFR & $\begin{array}{l}\text { Phase II } \\
\text { NCT04492293 }\end{array}$ & $\begin{array}{l}\text { Surgically unresectable or metastatic bladder urothelial } \\
\text { cancer with FGFRs genetic aberrations }\end{array}$ \\
\hline H3B-6527 & Eisai /H3 & FGFR4 & $\begin{array}{l}\text { Phase I } \\
\text { NCT02834780 }\end{array}$ & $\begin{array}{l}\text { Advanced hepatocellular carcinoma and intrahepatic } \\
\text { cholangiocarcinoma }\end{array}$ \\
\hline Fisogatinib (BLU-554) & Blueprint & FGFR4 & $\begin{array}{l}\text { Phase I } \\
\text { NCT02508467 }\end{array}$ & $\begin{array}{l}\text { FGF19 positive advanced hepatocellular carcinoma. } \\
\text { Results: ORR: 17\% VS 0\%; median PFS: } 3.3 \text { months VS } \\
2.3 \text { months (FGF19-positive VS FGF19-negative) }\end{array}$ \\
\hline
\end{tabular}

ORR objective response rate, $D C R$ disease control rate, $P F S$ progression-free survival, $O S$ overall survival, DOR duration of response, $C B R$ clinical benefit rate

NCT04083976), breast cancer (NCT03238196), liver cancer (NCT02421185) and castrated prostate cancer (NCT03999515). Subsequently, because of the excellent phase II results (Table 1, NCT02924376), FDA authorized FGFR-TKI Pemigatinib as the first targeted therapy for advanced cholangiocarcinoma in April 2020 [16, 17]. And various indications for Pemigatinib are undergoing clinical trials, such as nonmuscle invasive bladder cancer (NCT03914794), solid tumor (NCT03235570, NCT04258527, NCT03822117, NCT04003623), urothelial cancer (NCT04294277, NCT04003610, NCT02872714), acute myeloid leukemia (NCT04659616), myeloproliferative tumor (NCT03011372), colorectal cancer (NCT04096417), lung cancer and gastric cancer (NCT02393248).

In addition to these two approved FGFR-TKIs, numerous candidate FGFR-TKIs are developed and pushed into phase I or II clinical trials (Table 1). They include selective FGFR inhibitors, multi-target kinase inhibitors, covalent FGFR inhibitors, and FGFR4 specific inhibitors. And some of them have achieved significant progress based on clinical trials. For example, BGJ398 has been granted Fast Track Designation by FDA for treating cholangiocarcinoma with FGFR2 gene fusions due to the phase II study (NCT02150967) with an encouraging progression-free survival (PFS, 5.8 months), response rate (14.8\%), and disease control rate (75.4\%) [18]. By contrast, AZD4547 did not obviously improve PFS versus paclitaxel in gastric cancer patients harboring FGFR2 amplification [19].

Although the FGFR-TKIs have shown promising results in targeted therapies, resistance to FGFR-TKIs is becoming increasingly prominent. Here, we summarize the mechanism of FGFR-TKI resistance in cancer, and provide reasonable perspectives to overcome this resistance.

\section{Mutations in kinase, especially at gatekeeper residues, confer resistance to FGFR-TKI}

In a study of next-generation sequencing technology based on more than 4,000 tumors, FGFRs mutations account for around $26 \%$ of cancers with FGFRs gene abnormality [20]. FGFRs kinase mutations are the most common mechanism of FGFR-TKI resistance in targeted therapy. We categorize these mutations into gatekeeper mutations and other mutations. Gatekeeper residues are located in the Hinge region of the ATP-binding pocket of kinases. They play a role in controlling access of TKIs to the hydrophobic ATP binding pocket and advance active conformation of kinases through stabilizing the hydrophobic spine [21]. Other mutations-induced TKI resistances are relatively infrequent compared to gatekeeper mutations in FGFR, but they are still important (Table 2). For example, the FGFR1 N546K mutation confers resistance by increasing affinity for ATP [22]. The FGFR2 $\mathrm{N} 550 \mathrm{H}$ mutation is regarded as an auto-inhibitory molecule brake that restricts the kinase to be an uncontrolled active state $[23,24]$. The FGFR2 E565A mutation can upregulate the PI3K/AKT/mTOR signaling pathway [25]. Besides, FGFR2 mutations are present in $12 \%$ of endometrial cancers [26], in which FGFR2 S252W is the most common mutation (9\%) [27]. FGFR3 K650M mutation exists in $23.4 \%$ of FGFR mutated dedifferentiated liposarcomas, which predicts a poor prognosis [28].

\section{FGFR1 gatekeeper mutation}

Sohl and colleagues utilized structural and kinetic characteristics of FGFR1 to explain affinity changes for the FGFR inhibitors E3810 (Lucitanib) and AZD4547 due 
Table 2 Mutations induced FGFR-TKIs resistance

\begin{tabular}{|c|c|c|}
\hline TKI classification & TKI name & Mutation in kinase \\
\hline Pan-FGFR inhibitors & TAS-120 & FGFR2(V564F) \\
\hline \multirow[t]{3}{*}{ Multi-kinase inhibitors } & TKI258 & $\begin{array}{l}\text { FGFR1 (N546K); FGFR2(V564I,M536I,M538I,I548V,L618 } \\
\text { M,E719G,E565,K462,N550) }\end{array}$ \\
\hline & Ponatinib & FGFR1 (N546K); FGFR2(V564I); FGFR4(V550 E/L) \\
\hline & E3810 & FGFR1(V561M) \\
\hline \multirow[t]{6}{*}{ Selective FGFR inhibitors } & AZD4547 & $\begin{array}{l}\text { FGFR1(V561M); FGFR2(1567, N568, V581, E584G, } \\
\text { S587,K660E, K678M); FGFR3(V555M) }\end{array}$ \\
\hline & BGJ398 & FGFR2(N550H/K, V564F, E565A, K660M, L618V, K641R) \\
\hline & PD173074 & FGFR1(V561M, N546H); FGFR3(V555M) \\
\hline & AZ12908010 & FGFR3(V555M) \\
\hline & Debio 1347 & FGFR2(N550K, K660M, L618V) \\
\hline & BLU-554 & FGFR4(V550M/L, C552) \\
\hline
\end{tabular}

to the FGFR1 gatekeeper mutation V561M [29]. These studies showed that V561M mutation reduces affinity for E3810 (a double FGFR-VEGFR inhibitor), but that V561 mutant maintains nanomolar affinity for AZD4547 (a selective FGFR1-3 inhibitor) [29, 30]. Structurally, E3810 lacks flexibility, whereas the conformational flexibility of AZD4547 allows this TKI to adapt to the mutation [29, 31]. In addition, Sohl and colleagues used in vivo and in vitro binding assays to prove that the V561M mutant strongly activated STAT3 and produced significant resistance to AZD4547, thereby driving cancer progression [30]. By knocking out STAT3, cancer cells expressing FGFR1 V561M display restored sensitivity to AZD4547 [30]. These results suggest that knowledge of kinaseinhibitor complex structures alone is insufficient for a comprehensive understanding of the mechanisms of FGFR-TKI resistance. Downstream signaling pathways must also be considered.

\section{FGFR3 gatekeeper mutation}

FGFR3 resembles FGFR1 structurally. The V561M gatekeeper mutation of FGFR1 corresponds to the V555M gatekeeper mutation of FGFR3. TKI258 (Dovitinib), a poly-kinase inhibitor can simultaneously retain its inhibitory effect in patients with FGFR1 and FGFR3 gatekeeper mutations, but the FGFR1 V561M mutant is markedly less sensitive to PD173074 and AZD4547 [32, 33]. Initially, patients with the FGFR3-TACC3 fusion are highly sensitive to AZD4547, but this TKI becomes ineffective after the appearance of FGFR3 gatekeeper mutations $[32,34]$. Chell and his colleagues sequenced a KMS-11 myeloma cell line resistant to AZ12908010, and found the FGFR3 gatekeeper mutation V555M, which conferred cross-resistance to AZD4547 and PD173074 by an increase in FGFR3 phosphorylation and an improvement of downstream signaling transduction [34]. The molecular structural explanation is that the FGFR3 V555M mutation generates steric clashes with the phenyl ring of PD173074 by structural modeling, resulting in enhanced resistance [32, 34]. An additional factor is steric clashes caused by conformational changes in the P-loop region [22].

\section{FGFR2 gatekeeper mutation}

In a clinical study of three patients with FGFR2-fusion cholangiocarcinoma receiving BGJ398 therapy, all patients developed acquired resistance with FGFR2 gatekeeper V564F mutation [35]. In the BaF3 cell line, which has high FGFR2 expression, researchers identified several Dovitinib-resistant mutations, including gatekeeper mutation [23]. Ponatinib (AP24534), a third-generation TKI, effectively inhibits all Dovitinib-resistant FGFR2 mutants except gatekeeper mutation [23]. Ponatinib, as a type II inhibitor, targets the inactive and DFG-out conformation, but can also target the active conformation [36].

Goyal et al. reported that the irreversible covalent FGFR inhibitor TAS-120 overcomes drug resistance induced by ATP-competitive FGFR inhibitors (such as BGJ398 and Debio 1347) in patients with FGFR2 fusionpositive intrahepatic cholangiocarcinoma [37]. Structurally, the FGFR2 gatekeeper V564F mutation induces steric clashes with the dichloro dimethoxy phenyl ring of BGJ398 [32, 35]. Debio 1347 generally retains activity against the FGFR2 V564F gatekeeper mutation, due to Debio 1347 partially replacing the large dimethoxyphenyl group with a benzimidazole moiety that makes stable contacts with V564F. Debio 1347 also confers resistance to other FGFR2 mutations [37, 38]. TAS-120 binds its target covalently, but it cannot resist FGFR2 gatekeeper mutations, due to steric clashes $[37,39]$. 


\section{FGFR4 gatekeeper mutation}

It is worth noting that mutations in FGFR4 are rare, but that Hatlen et al. identified gatekeeper mutations (V550M/L) and Hinge-1 (C552) mutations in the FGFR4 kinase domain from hepatocellular carcinoma patients after treatment with the selective FGFR4 inhibitor Fisogatinib (BLU-554) [40]. These mutants prevented Fisogatinib from covalently binding to FGFR4 [37]. Besides, FGFR4 V550M mutation was found in 13\% of neuroendocrine breast cancers, and FGFR4 V550L mutation was found in $9 \%$ of embryonal rhabdomyosarcoma tumors $[41,42]$. Huang et al. found that FGFR4 V550L mutant forms steric clashes with the imidazo[1,2-b]pyridazine scaffold of Ponatinib. Both preventing covalent binding and conflict formation reduced the inhibitory activity of TKI [43]. Surprisingly, our group found by in vivo and in vitro experiments that the Pan-FGFR inhibitor
LY2874455 has a remarkable ability to overcome FGFR4 gatekeeper mutation-induced TKI resistance [44]. Further crystallographic experiment proved that LY2874455 binding site is distant from the gatekeeper residue, which avoids steric clashes with the ATP-binding pocket of FGFR4 [44, 45].

\section{Strategies for overcoming mutation-based FGFR-TKI resistance}

When designing TKIs for FGFR gatekeeper mutations, we should take into account the following considerations: (1) The binding site for inhibitors can be far from the hinge region and, especially, from gatekeeper residues. For example, the pan-FGFR inhibitor LY2874455 is reported to be the most effective compound for all the different resistance mutations (Fig. 1a) [35, 40, 44]. The clinical phase I study showed that LY2874455 had nice

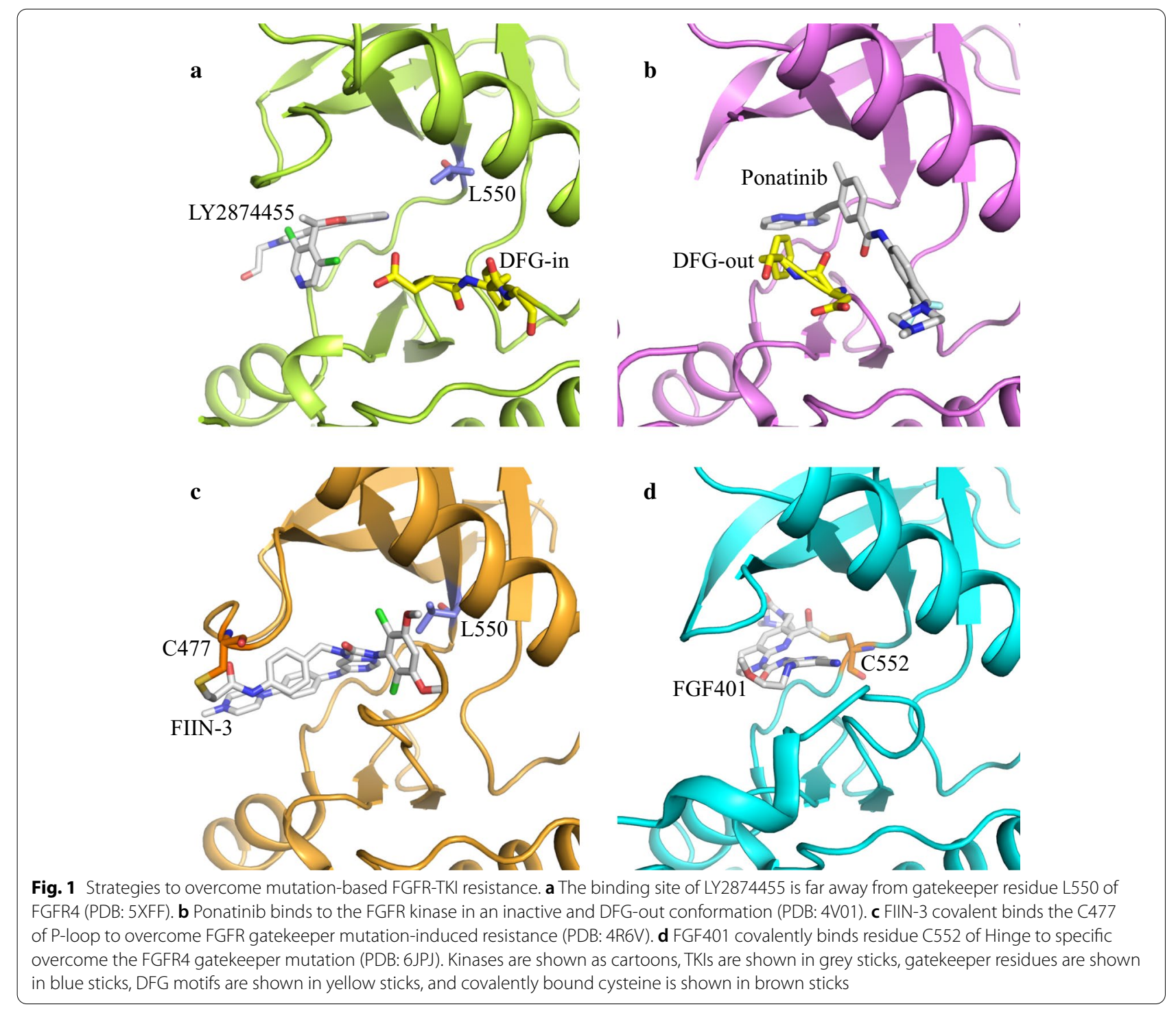


tolerability and activity with an effective half-life of $12 \mathrm{~h}$, weak toxicities, and RP2D (recommended phase 2 dosing) of $16 \mathrm{mg}$ BID (bis in die) in patients with advanced solid-organ cancer [46]; (2) The inhibitors can selectively inhibit the active conformation of the kinase. Ponatinib binds to FGFR kinases in an inactive and DFG-out conformation (Fig. 1b) with IC50 of nanomolar in preclinical studies. And it is in phase II (NCT02272998) to treat advanced solid tumor patients with FGFR2-activated mutations [47]. However, Ponatinib is a multi-target kinase inhibitor that may cause strong side effects; (3) Cys-mediated covalent inhibitors can overcome gatekeeper mutations. FIIN-2 and FIIN-3 are the first covalent inhibitors based on the PD173074 scaffold. They can effectively bind covalently to C477 of the P-loop to overcome FGFR TKI resistance caused by FGFR gatekeeper mutations (Fig. 1c) [48]. Another case is FGF401, which covalently binds the C552 of Hinge to specifically overcome FGFR4 gatekeeper mutations (Fig. 1D) [49]. At present, FGF401 is in clinical phase I/II trials for hepatocellular carcinoma patients with FGF19/FGFR4 signal abnormity [50]. These covalent inhibitors with both selectivity and flexibility may be the main focus of targeted drug development in the future [51-53].

\section{Lysosome-mediated TKI sequestration reduces the kinase accessibility of TKI}

Computer-aided drug models and the application of structural biology can reveal interactions between drugs and their targets in vitro. However, kinetic changes of anticancer drugs in cells can also affect their efficacy, and even cause drug resistance. Lysosomes are digestive vesicles composed of a lipoprotein membrane. They contain various acidic hydrolases that eliminate excess proteins, nucleic acids, lipids, polysaccharides, and other macromolecules in the cell [54-56]. It is also an ideal container for sequestration of weakly base TKIs away from their targets, which changes the kinetics of TKIs and results in drug resistance. Lysosomes mediate TKI sequestration in the following ways (Fig. 2).

\section{Lipophilic weakly basis TKIs are sequestrated into lysosome by diffusion}

After lipophilic weakly basic TKIs enter the cell, they can diffuse freely into lysosomes, driven by the $\mathrm{pH}$ gradient change between lysosomes and cytoplasm. The drug is then protonated in an acidic environment and cannot recross the lysosomal membrane. It is sequestrated in the lysosomal vesicle, which prevents the drug from reaching its target, resulting in a decrease in drug concentration and drug resistance [55]. Sunitinib and Gefitinib (a selective EGFR-TKI) were reported to have a significant sequestration effect in lysosomes $[55,57]$.
Englinger and colleagues have documented lysosomeinduced drug sequestration in lung cancer with FGFR changes. They analyzed the cell-free fluorescence, intracellular accumulation, and distribution of the multikinase inhibitor Nintedanib and the FGFR kinase inhibitor PD173074 using three-dimensional fluorescence spectroscopy, together with analytical chemistry and molecular biology methods. These studies revealed selective accumulation of drugs in the lysosome, and verified the lipophilic and weakly basic drug characteristics of Nintedanib and PD173074 [58-60]. However, this mechanism is reversible and has a less stable genetic resistance effect [61]. Targeting lysosomes in tumors therapy can be a promising strategy to overcome drug resistance. Besides, autophagy is closely related to lysosome-mediated TKI resistance [62]. Rui Peng and colleagues found that activation of the AMPK/mTOR signaling pathway induced survival autophagy to resist drug therapy in FGFR-TKI resistant gastric cancer cell lines. And TAK1 (TGF- $\beta$-activated kinase 1) over-expression enhanced the activation of AMPK signaling and autophagy. Further in vitro and in vivo studies demonstrated that the TAK1 inhibitor NG25 and FGFR inhibitor AZD4547 synergistically inhibited proliferation and autophagy in AZD4547resistant cell lines and patient-derived xenograft tumor model [63]. It suggests that TAK1 inhibitors cooperated with FGFR inhibitors may be a new therapeutic strategy to overcome autophagy-mediated FGFR-TKI resistance.

\section{$A B C$ transporters pump TKI into the lysosome}

ATP-binging cassette $(\mathrm{ABC})$ superfamily transporters are located on cytoplasmic and lysosomal membranes. Cytoplasmic $\mathrm{ABC}$ transporters pump TKIs out of the cytoplasm. Lysosomal ABC transporters pump TKI into lysosomes. This process promotes the sequestration of TKIs in lysosomes [56, 64]. For example, ABCG2 can mediate active transport of Imatinib into lysosomes [65]. Moreover, $\mathrm{ABC}$ transporters can cooperate with lysosome sequestration to aggravate drug resistance [66].

\section{TFEB-mediated lysosome biosynthesis enhances TKI sequestration}

TFEB, as a key transcription factor, regulates the biogenesis of lysosomes. Under physiological conditions, Ser142 of TFEB is phosphorylated by lysosomal mammalian target rapamycin complex 1 (mTORC1), and the phosphorylated TFEB is retained in the cytoplasm by forming a complex with YWHA (14-3-3) protein, resulting in inactive transcription. In contrast, lysosome-sequestrated TKI is protonated in an acidic environment, which increases the permeability of lysosomal membrane via fluidization and inhibits the activity of mTORC1 kinase. The high permeability of the lysosomal 


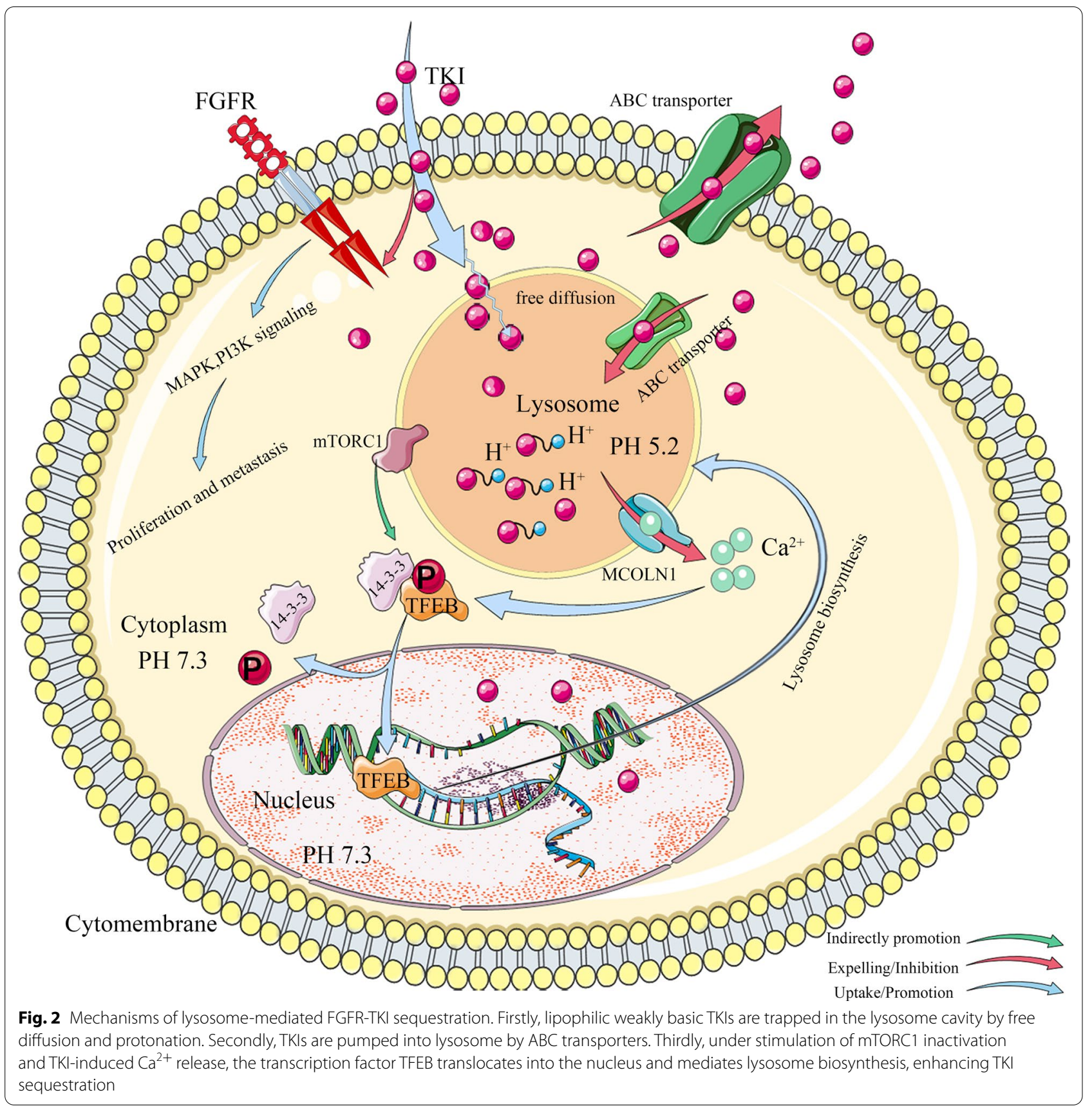

membrane increases the release of $\mathrm{Ca}^{2+}$ into cytoplasm to activate calcineurin, which further dephosphorylates TFEB. Dephosphorylated TFEB then dissociates from the 14-3-3/TFEB complex, and enters into the nucleus to initiate transcription of lysosome-associated proteins. In this way, TFEB promotes lysosome generation and increases TKI sequestration and resistance [67-69].

\section{Intervention strategies for lysosome sequestration of TKI}

The most direct way to prevent lysosome sequestrationinduced drug resistance is to change the structure of the TKI [56], such as by assembling the TKI onto nanoparticles for delivery into the cell [70]. Another way is targeting the lysosome to eliminate lysosome-mediated TKI sequestration [56, 71]. This approach can involve: (1) Targeting the H+ATP enzyme (maintaining lysosome acidity) to alkalize lysosomes; (2) Lysosomotropic agents, like chloroquine, disturb lysosomal sequestration of TKIs 
by inhibiting autophagy or de-acidification [56, 66]; (3) Imidazoacridones (IAS) can cause lysosomal photodestruction, which destroys the internal structure of lysosomes [72]; (4) Acid sphingomyelinase (ASM) inhibitors and lysosomal membrane protein (LMP) inhibitors can destroy the stability of the lysosomal membrane and alter membrane permeability [59], which is essential to maintain the $\mathrm{pH}$ gradient between lysosome and cytoplasm. Blocking TFEB-mediated lysosomal generation should also be an effective strategy to reduce FGFR-TKI sequestration. Lastly, we can combine kinase inhibitors with autophagy inhibitors and $\mathrm{ABC}$ transporter-related inhibitors to overcome resistance. For example, ABCB1 has been reported to be a key player in resistance to the multiple-target kinase inhibitor Nintedanib [73, 74]. Inhibition of ABCB1 and kinases simultaneously should be a promising strategy for overcoming resistance [75-77].

\section{Alternatively activated signaling pathways bypass FGFR inhibition}

FGFR-TKI resistance mediated by signaling pathways involves alternative activation of two downstream branches of the FGFR signal (PI3K-AKT and RASMAPK) and other membrane RTKs pathways (Fig. 3).

\section{PI3K-AKT activation}

Secondary activation of the PI3K-AKT signaling pathway is a classical mechanism for FGFR-TKI resistance [78].
Jharna Datta and colleagues found that the phosphorylation levels of AKT and downstream GSK3 were up-regulated in BGJ398 resistant DMS114 (FGFR1-amplificated SCLC) and RT112 (urothelial carcinoma with FGFR aberrations) cell lines. And the drug-resistant cell lines recovered their sensitivity to BGJ398 after blocking the PI3K-AKT signal by AKT inhibitor GSK2141795 or siRNA intervention [79].

The PI3K-AKT signaling pathway can be directly regulated by Pleckstrin Homology-Like Domain family A member 1 (PHLDA1) and Phosphatase and tensin homolog (PTEN), resulting in TKI-resistance (Fig. 3) [78]. PHLDA1 can competitively bind PIP3 with AKT to inhibit the activity of AKT. Once PHLDA1 is knocked down, the continuous activation of AKT signaling is sufficient to sustain cell proliferation and survival, which can induce new resistance to FGFR inhibitors PD173074 and AZD4547 in endometrial cancer cells [80]. PTEN belongs to the protein tyrosine phosphatases (PTP) gene family. Knockout of PTEN can enhance the phosphorylation of AKT, and up-regulate the expression of PIK. It suggests that PTEN deletion is a potential mechanism to resist FGFR inhibition in endometrial cancer cells [8183]. Besides, GSK3, as a downstream molecule of PI3KAKT signaling, can also be activated by PKC signal in an AKT-independent manner, leading to resistance to FGFR inhibitor AZD4547 in Diffuse-Type Gastric Cancer [84].

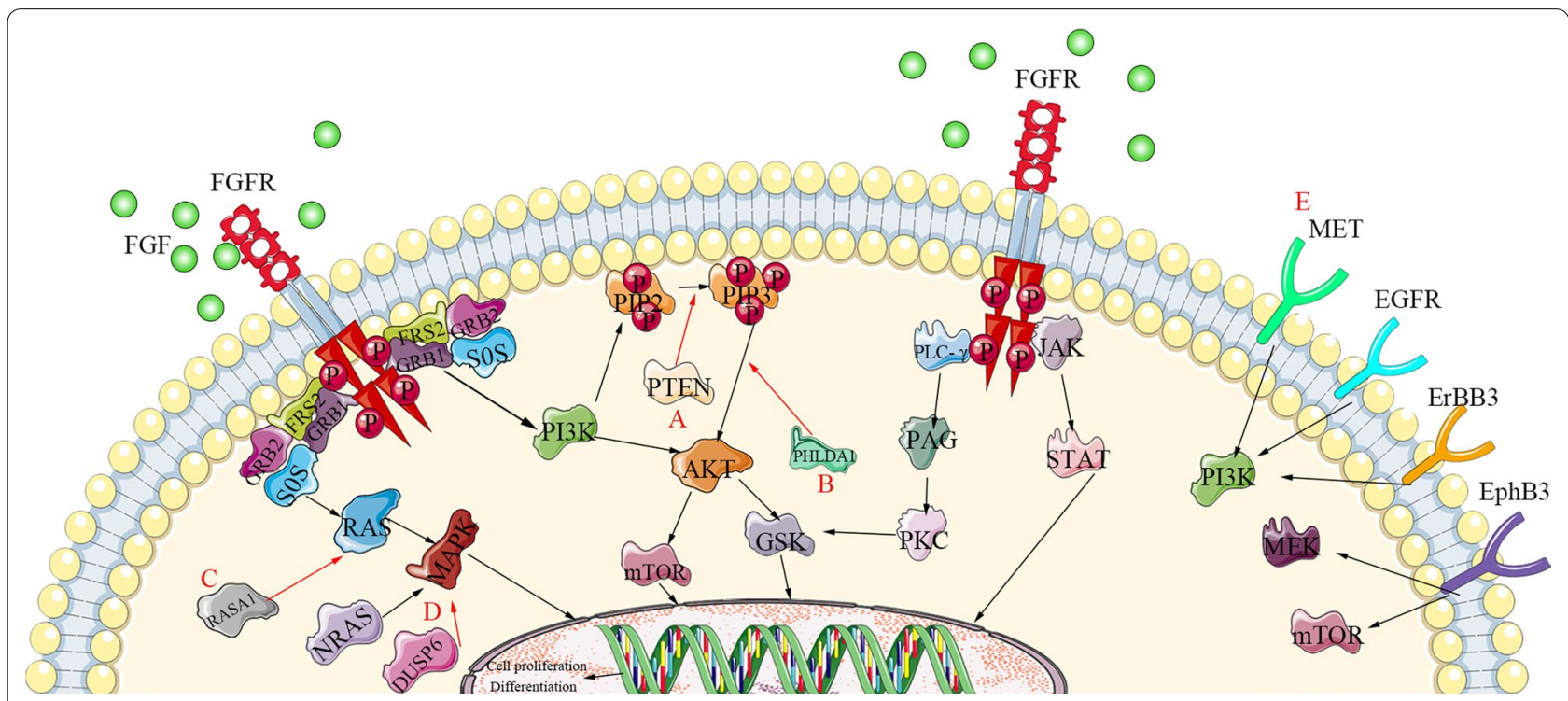

Fig. 3 Mechanisms of alternative signaling activation induced FGFR-TKI resistance. FGFR signaling pathway regulation networks are shown in black arrows. Mechanisms of FGFR-TKI resistance caused by feedback signaling activation are shown. a Loss of PTEN up-regulates the expression of PIK kinase via interfering with the conversion of PIP2 to PIP3 and abortively activates AKT; $\mathbf{b}$ inactivation of PHLDA1 continuously activates AKT signaling by competitively binding AKT with PIP3; $\mathbf{c}$ inactivation of RASA1 directly activates RAS-MAPK pathway through regulating the active transformation of RAS; $\mathbf{d}$ NRAS amplification and DUSP6 deletion stimulate activation of the MAPK pathway; e alternative activation of cytomembrane localized kinases, such as EGFR, MET and ErbB3, bypass FGFR signaling pathway 


\section{RAS-MAPK activation}

Increased activation of the RAS-MAPK pathway plays a critical role in FGFR-TKI resistance [78, 85] Kas and colleagues showed that Ras p21 protein activator 1 (RASA1) is a negative regulator of RAS, whose inactivation directly causes activation of the RAS-MAPK pathway [86]. For instance, knockdown of RASA1 activated downstream signaling of RAS, promoting cell growth and causing resistance to FGFR inhibition. In contrast, the recovery of RASA1 expression in RASA1-mutated cells reduced MAPK and PI3K signaling pathways [86, 87].

In addition, as positive and negative factors in regulating MAPK signaling pathways, abnormalities of NRAS and DUSP6 may affect FGFR-TKI resistance. For example, in drug-resistant lung cancer cells, NRAS amplification [88] and DUSP6 deletion lead to a reactivation of the MAPK pathway, thereby resisting FGFR inhibitors [89]. Co-inhibition of FGFR and MAPK pathway by FGFR inhibitors and MEK inhibitor Trametinib induced tumor degradation in tumor xenografts derived from mesenchymal-like KRAS mutant cancer cell lines as well as patient-derived xenograft model with a typical mesenchymal phenotype [90].

\section{Membrane RTKs activation}

Alternative activation of membrane RTKs, such as ErbB3 [91, 92], MET [93, 94], EGFR [95], EphB3 [96, 97], KIT [98], and the crosstalk between RTK and FGFR, account for the resistance of FGFR targeted therapies [99, 100]. A functional genetic screen has found that feedback activation of ErbB3 (Erb-B2 receptor tyrosine kinase 3) signaling pathway can reduce the sensitivity of AZD4547 through activation of downstream PI3K pathway in urothelial carcinoma [91]. Notably, ligand-mediated activation of ErbB2/3 can directly lead to BGJ398 resistance in FGFR3-dependent cancer cells [92].

Singleton et al. found that the activation of MET plays a crucial role in resistance to the FGFR inhibitor AZ8010 [93]. Smurm Kim et al. proved that the enhanced MET can activate PI3K/AKT signaling pathway in an ErbB3dependent or independent manner to obtain resistance to FGFR-TKIs [94]. Moreover, MET and FGFR can compensate for each other by regulating the activation of downstream signaling pathways [101].

Using parallel RNA interference genetic screens, Maria and colleagues demonstrated that the activation of EGFR can limit the sensitivity of PD170374 in bladder cancer. Combination of FGFR and EGFR inhibitors by PD173074 and Gefitinib overcome this resistance in vitro and in vivo, but with poor tolerance in mice [95]. On the contrary, activation of the FGFR signaling pathway also associates with resistance to EGFR inhibitors [102].
Lee et al. reported that the EphB3 signaling pathway was alternatively activated in FGFR inhibitor AZD4547 resistant gastric cancer cell line SNU-16R, thereby promoting epithelial-to-mesenchymal transition (EMT) of gastric cancer cell through activation of Ras-ERK1/2-mTOR pathway [96, 97]. Blocking EphB3 by LDN-211904 reduced the phosphorylation of the Ras-ERK1/2-mTOR signal and inhibited EMT in SNU-16R cells [96]. The reactivation of mTOR signaling also reduced the sensitivity of FGFR2amplified tumors to AZD4547 [96].

Bauer and colleagues found that KIT activation was 3-6 folds higher in GIST430 and GIST48 (Imatinibresistant gastrointestinal stromal tumor) than in GIST882 (Imatinib-sensitive) [98]. And targeting downstream signaling molecular PI3K resulted in substantial apoptosis in the Imatinib-resistant gastrointestinal stromal tumor [98]. Besides, signaling crosstalk between KIT and FGFR3 activated the MAPK pathway to promote resistance to Imatinib. Co-inhibition of KIT and FGFR3 synergistically blocked the growth of Imatinib-resistant cells [103].

\section{Strategies for blocking alternatively activated signaling}

To overcome drug resistance, maintaining a high response rate to kinase inhibitors is essential. One approach employs combination therapy, which can block multiple activation pathways simultaneously [104]. For example, in ovarian cancer xenografted mice, co-inhibition of FGFR and mTOR pathway simultaneously by BGJ398 and rapamycininduced tumor regression, cell cycle arrest, and apoptosis [105]. Intriguingly, FGFR2-TACC3 fusion protein identified in cholangiocarcinoma appears to be a client of heat shock protein 90 (HSP90). The HSP90 inhibitor Ganetespib combined with BGJ398 can greatly inhibit signaling transduction of FGFR2-TACC3 fusion protein [106]. In addition, combination therapy with immune checkpoint inhibitors and combination endocrine therapy with hormonal changes in cancer patients have been reported [107, 108]. For example, co-inhibition of FGFR and PD-1 by Erdafitinib and Cetrelimab (PD-1 targeted monoclonal antibody) is in phase Ib /phase II (NCT03473743) against previously untreated cisplatin-ineligible patients [109].

Combination therapy has great promise, but it may elicit undesirable drug-drug interactions. Therefore, another approach is rationally designing single compounds with dual targets [110]. As a pan-inhibitor of FGFR1-3, 3D185 not only inhibits FGFR in tumor cells but also target CSF$1 R$ (the main survival factor of macrophages), which is vital to the immunosuppressive microenvironment [111]. Another dual-targeted inhibitor is MPT0L145, which targets PIK3C3 and FGFR simultaneously [112]. These double active inhibitors provide new approaches to drug design. 


\section{Gene fusion enhances the activation of downstream signaling}

The term gene fusion refers to gene rearrangements caused by chromosome inversion, interstitial deletion, repetition, or translocation, which are prevalent in various cancers [113]. Oncogene fusions can constitutionally activate tyrosine kinases and enhance downstream survival signaling. Hence, gene fusions have a significant effect on the development of many solid tumors [113].

FGFR gene fusions directly account for FGFR-TKI resistance FGFR-TKI resistance events can be directly triggered by FGFR gene fusion [114]. Kim and colleagues identified a novel FGFR2-ACSL5 fusion from a metastatic gastric cancer patient with FGFR2 amplification through RNA sequencing [115]. Intriguingly, at the beginning of FGFR inhibitor treatment, the patient showed strong sensitivity to LY2874455, and no FGFR2-ACSL5 fusion was found in vivo, but eventually, drug resistance was detected along with the FGFR2-ACSL5 fusion gene [115]. Additionally, PIK3-AKT-mTOR pathways were greatly activated in gene fusion- expressing cell lines [115]. However, this study represents an individual case and is not generalized. The function of FGFR2-ASCL5 fusion proteins is not yet clear and maybe affected by tumor heterogeneity and body environment.

\section{JHDM1D-BRAF gene fusion indirectly induces FGFR-TKI resistance}

The occurrence of FGFR-TKI resistance events can also be triggered by other related gene fusion. Sase et al. performed a study on the mechanism of resistance to FGFR small molecule inhibitors in FGFR2-amplified gastric cancer. They found that the fusion kinase JHDM1DBRAF located on chromosome 7 confers resistance to AZD4547 in a monoclonal gastric cancer cell line SUN16. Jumonji $\mathrm{C}$ domain-containing histone demethylase
1 homolog D (JHDM1D) is a histone demethylase that plays a major role in neural differentiation [116]. BRAF, which regulates the MAPK/ERK signaling pathway, encodes the RAF family of serine/threonine protein kinases [117]. After JHDM1D-BRAF fusion, constructive dimerization of the fusion protein was enhanced, accompanied by activation of the downstream MAPK pathway, the disappearance of FGFR2 phosphorylation, and a decrease in FGFR2 expression in SUN-16 cells. These results suggest that co-treatment of RAF dimer inhibitors with downstream signaling molecule MEK inhibitors may be an option for avoiding resistance [118] (Table 3).

\section{Conclusions}

With the increase in FGFR inhibitors undergoing clinical or pre-clinical trials, the resistance to FGFR-TKIs has become a major issue. The main mechanisms responsible for resistance can be summarized as follows: (1) Gatekeeper mutation-induced steric clashes that interfere with TKI binding; (2) Feedback activation of alternative signaling pathways that bypass FGFR inhibition; (3) Lysosome sequestration-mediated TKI "kidnapping" that promotes TKI retention in lysosomes and prevents TKIs from reaching their target kinases; (4) Gene fusions that induce continuous activation of downstream signaling, thereby eliminating the inhibition of TKI.

In addition, the acquired resistance mediated by FGFFGFR signal axis should be considered. (1) Activation of the FGF2-FGFR1 autocrine pathway results in acquired resistance to Gefitinib in NSCLC $[119,120]$. (2) Nuclear translocation of FGF2/FGFR1 facilitates pancreatic cancer cell invasion, leading to TKIs resistance [121]. (3) FGFR1 amplification induces receptor accumulation and continuously activates the downstream signaling pathways [122], and (4) abnormally up-regulated FGFR ligands disrupt the autocrine loop of growth factor, leading to lung cancer resistance to TKIs [120].

Table 3 The mechanisms of FGFR-TKIs resistance

\begin{tabular}{|c|c|c|}
\hline TKI classification & TKI name & Involved mechanisms \\
\hline Pan-FGFR inhibitors & LY2874455 & FGFR2-ACSL5 fusion \\
\hline \multirow[t]{2}{*}{ Multi-kinase inhibitors } & Ponatinib & PTEN \\
\hline & Nintedanib & ABCB1 induced drug-efflux; Lysosomal sequestration \\
\hline \multirow[t]{4}{*}{ Selective FGFR inhibitors } & AZD4547 & $\begin{array}{l}\text { Gene fusion: JHDM1D-BRAF fusion; Alternative pathways } \\
\text { activation: RAS-MAPK pathway, ErbB3/PI3KAKT pathway, } \\
\text { MET; Related molecular abnormalities: RASA1, PHLDA1, PTEN, } \\
\text { STAT3; Other: EMT; Drugs-efflux }\end{array}$ \\
\hline & BGJ398 & $\begin{array}{l}\text { Alternative pathways activation: RAS-MAPK pathway, PI3K } \\
\text { AKT /GSK pathway, MET, ErbB2/3 pathway; Related molecular } \\
\text { abnormalities: NRAS, DUSP6; Other: EMT }\end{array}$ \\
\hline & PD173074 & EGFR signaling pathway; PHLDA1; EMT; Lysosomal sequestration \\
\hline & AZ12908010 & MET \\
\hline
\end{tabular}


Therapeutic strategies for overcoming FGFR TKI resistance mainly center on four approaches: (1) Developing new FGFR TKIs, especially covalent inhibitors, to specifically overcome mutation-induced TKI resistance; (2) Adopting combination therapies that target multiple pathways simultaneously; (3) Disrupting the architecture of lysosomes to release sequestrated TKI; and (4) Exploiting FGFR ligand or FGFR specific monoclonal antibodies to bypass TKI resistance [107, 123].

The potential strategies to predict and bypass TKI resistance can prospect from the following three aspects: (1) Developing computer machine learning algorithm by multivariable models to predict TKI resistance factors for early diagnosis and intervention of patients with drug resistance, which have achieved big progress on individualized therapy of patients with acquired EGFR-TKI resistance [124]; (2) Exploiting Physics-Based and Data-Driven Approaches to screen inhibitors through predicting affinity changes between TKIs and kinases based on kinase mutations, reducing the occurrence of TKI resistance $[125,126]$; (3) Adopting next-generation sequencing (such as ctDNA sequencing), molecular detection, and tumor biopsy detection of FGFR gene abnormalities in patients to predict/bypass the occurrence of TKI resistance and evaluate appropriate treatment regimen [127, 128]. In a word, the ultimate goal of FGFR-TKI targeted therapy should be to move toward precision medicine and individualized treatment to develop optimal treatment strategies.

\begin{abstract}
Abbreviations
FGFR: Fibroblast growth factor receptor; FGF: Fibroblast growth factor; TKI: Tyrosine kinase inhibitor; STAT3: Signal transducer and activator of transcription; TACC3: Transforming acidic coiled-coil containing protein3; PI3K: Phosphatidylinositol 3-kinase; AKT: AKT serine/threonine kinase; mTOR: Mechanistic target of rapamycin kinase; PHLDA1: Protein Pleckstrin Homology-Like Domain, family A, member 1; PTEN: Phosphatase and tensin homolog; PTP: Protein tyrosine phosphatases; PIP3: Plasma membrane intrinsic protein 3; GS3KB: Glycogen synthase kinase 3 beta; PKC: Protein kinase C; ErbB3: Erb-B2 receptor tyrosine kinase 3; EGFR: Epidermal growth factor receptor; RTK: Receptor tyrosine kinase; KIT: KIT proto-oncogene, receptor tyrosine kinase; MAPK: Mitogen-activated kinase-like protein; EMT: Epithelial mesenchymal transition; MET: MET proto-oncogene, receptor tyrosine kinase; RASA1: Ras p21 protein activator 1; EphB3: Eph receptor B3; MEK: MAP kinase-ERK kinase; VEGFR: Vascular endothelial growth factor receptor; ABC: ATP-binging cassette; TFEB: Transcription factor EB; mTORC1: Mammalian target rapamycin complex 1; IAS: Imidazoacridones; ASM: Acid sphingomyelinase; LMP: Lysosomal membrane protein; ACSL5: Acyl-CoA synthetase long chain family member 5; JHDM1D: Jumonji C domain containing histone demethylase 1 homolog D; BRAF: B-Raf proto-oncogene; TAK1: TGF- $\beta$-activated kinase 1; RP2D: Recommended phase 2 dosing; BID: Bis in die; AMPK: AMP-activated protein kinase; ORR: Objective response rate; DCR: Disease control rate; PFS: Progression-free survival; OS: Overall survival; DOR: Duration of response; CBR: Clinical benefit rate.
\end{abstract}

\section{Acknowledgements}

We would like to thank Roy A Mariuzza (University of Maryland) for critical proofreading.

\section{Authors' contributions}

$Y C$ and DW conceived and supervised the project; SY, YL, JW, and DW wrote the paper, $X C$ and ML provided critical suggestions; SY, YC, and DW revised the paper. All authors read and approved the final manuscript.

\section{Funding}

This work was supported by grants from the National Natural Science Foundation of China (81974074 and 81570537), Outstanding Youth Project of Hunan Education Department (19B475), Open Project of State Local Joint Engineering Laboratory for Anticancer Drugs (KAYW-FK-20-01), Scientific Research Foundation of the University of South China (190XQD016).

Availability of data and materials

The materials supporting the conclusion of this review have been included in the article.

\section{Ethics approval and consent to participate}

Not applicable.

\section{Consent for publication \\ Not applicable.}

\section{Competing interests}

The authors declare that they have no competing interests.

\section{Author details}

${ }^{1}$ Department of Oncology, Laboratory of Structural Biology, NHC Key Laboratory of Cancer Proteomics, State Local Joint Engineering Laboratory for Anticancer Drugs, Xiangya Hospital, Central South University, Changsha 410008, Hunan, China. ${ }^{2}$ Clinical Anatomy and Reproductive Medicine Application Institute, Department of Histology and Embryology, Hunan Province Key Laboratory of Cancer Cellular and Molecular Pathology, University of South China, Hengyang 421001, China. ${ }^{3}$ National Clinical Research Center for Geriatric Disorders, Xiangya Hospital, Central South University, Changsha, Hunan 410008, China. ${ }^{4}$ W.M. Keck Laboratory for Structural Biology, University of Maryland Institute for Bioscience and Biotechnology Research, Rockville, MD 20850, USA.

Received: 29 October 2020 Accepted: 1 February 2021

Published online: 10 February 2021

\section{References}

1. Xue W, Li M, Chen L, Sun L, Li Y. Recent developments and advances of FGFR as a potential target in cancer. Future Med Chem. 2018;10(17):2109-26.

2. Dieci M, Arnedos M, Andre F, Soria J. Fibroblast growth factor receptor inhibitors as a cancer treatment: from a biologic rationale to medical perspectives. Cancer Discov. 2013;3(3):264-79.

3. Krause D, Van Etten R. Tyrosine kinases as targets for cancer therapy. $N$ Engl J Med. 2005;353(2):172-87.

4. Regeenes R, Silva P, Chang H, Arany E, Shukalyuk A, Audet J, et al. Fibroblast growth factor receptor 5 (FGFR5) is a co-receptor for FGFR1 that is up-regulated in beta-cells by cytokine-induced inflammation. J Biol Chem. 2018;293(44):17218-28.

5. Trueb B. Biology of FGFRL1, the fifth fibroblast growth factor receptor. Cell Mol Life Sci CMLS. 2011;68(6):951-64.

6. Mikhaylenko D, Alekseev B, Zaletaev D, Goncharova R, Nemtsova M. Structural alterations in human fibroblast growth factor receptors in carcinogenesis. Biochem Biokhimiia. 2018;83(8):930-43.

7. Babina I, Turner N. Advances and challenges in targeting FGFR signalling in cancer. Nat Rev Cancer. 2017;17(5):318-32.

8. Turner N, Grose R. Fibroblast growth factor signalling: from development to cancer. Nat Rev Cancer. 2010;10(2):116-29.

9. Gnatenko DA, Kopantzev EP, Sverdlov ED. Fibroblast growth factors and their effects in pancreas organogenesis. Biomed Khim. 2017:63(3):211-8

10. Czyz M. Fibroblast growth factor receptor signaling in skin cancers. Cells. 2019;8(6):540. 
11. Katoh M. FGFR inhibitors: effects on cancer cells, tumor microenvironment and whole-body homeostasis (review). Int J Mol Med. 2016;38(1):3-15.

12. Tiong K, Mah L, Leong C. Functional roles of fibroblast growth factor receptors (FGFRs) signaling in human cancers. Apoptosis Int J Program Cell Death. 2013;18(12):1447-68

13. Dai S, Zhou Z, Chen Z, Xu G, Chen Y. Fibroblast growth factor receptors (FGFRs): structures and small molecule inhibitors. Cells. 2019;8(6):614.

14. Loriot $Y$, Necchi A, Park SH, Garcia-Donas J, Huddart R, Burgess E, et al. Erdafitinib in locally advanced or metastatic urothelial carcinoma. N Engl J Med. 2019;381(4):338-48.

15. Montazeri K, Bellmunt J. Erdafitinib for the treatment of metastatic bladder cancer. Expert Rev Clin Pharmacol. 2020;13(1):1-6.

16. Abou-Alfa GK, Sahai V, Hollebecque A, Vaccaro G, Melisi D, Al-Rajabi R, et al. Pemigatinib for previously treated, locally advanced or metastatic cholangiocarcinoma: a multicentre, open-label, phase 2 study. Lancet Oncol. 2020;21(5):671-84.

17. Hoy S. Pemigatinib: first approval. Drugs. 2020;80(9):923-9.

18. Javle M, Lowery M, Shroff R, Weiss K, Springfeld C, Borad M, et al. Phase II study of BGJ398 in patients with FGFR-altered advanced cholangiocarcinoma. J Clin Oncol. 2018;36(3):276-82.

19. Van Cutsem E, Bang Y, Mansoor W, Petty R, Chao Y, Cunningham D, et al. A randomized, open-label study of the efficacy and safety of AZD4547 monotherapy versus paclitaxel for the treatment of advanced gastric adenocarcinoma with FGFR2 polysomy or gene amplification. Ann Oncol. 2017;28(6):1316-24

20. Helsten T, Elkin S, Arthur E, Tomson B, Carter J, Kurzrock R. The FGFR landscape in cancer: analysis of 4,853 tumors by next-generation sequencing. Clin Cancer Res. 2016:22(1):259-67.

21. Liu Y, Shah K, Yang F, Witucki L, Shokat KM. A molecular gate which controls unnatural ATP analogue recognition by the tyrosine kinase v-Src. Bioorg Med Chem. 1998;6(8):1219-26.

22. Yoza K, Himeno R, Amano S, Kobashigawa Y, Amemiya S, Fukuda N, et al. Biophysical characterization of drug-resistant mutants of fibroblast growth factor receptor 1. Genes Cells. 2016;21(10):1049-58.

23. Byron SA, Chen H, Wortmann A, Loch D, Gartside MG, Dehkhoda F, et al. The N550K/H mutations in FGFR2 confer differential resistance to PD173074, dovitinib, and ponatinib ATP-competitive inhibitors. Neoplasia. 2013;15(8):975-88.

24. Chen H, Ma J, Li W, Eliseenkova AV, Xu C, Neubert TA, et al. A molecular brake in the kinase hinge region regulates the activity of receptor tyrosine kinases. Mol Cell. 2007;27(5):717-30.

25. Krook MA, Lenyo A, Wilberding M, Barker H, Dantuono M, Bailey KM, et al. Efficacy of FGFR inhibitors and combination therapies for acquired resistance in FGFR2-fusion cholangiocarcinoma. Mol Cancer Ther. 2020;19(3):847-57.

26. Dutt A, Salvesen H, Chen T, Ramos A, Onofrio R, Hatton C, et al. Drugsensitive FGFR2 mutations in endometrial carcinoma. Proc Natl Acad Sci USA. 2008:105(25):8713-7.

27. Krakstad C, Birkeland E, Seidel D, Kusonmano K, Petersen K, Mjøs S, et al. High-throughput mutation profiling of primary and metastatic endometrial cancers identifies KRAS, FGFR2 and PIK3CA to be frequently mutated. PLoS ONE. 2012;7(12):e52795.

28. Li C, Shen Y, Ren Y, Liu W, Li M, Liang W, et al. Oncogene mutation profiling reveals poor prognosis associated with FGFR1/3 mutation in liposarcoma. Hum Pathol. 2016;55:143-50.

29. Sohl CD, Ryan MR, Luo B, Frey KM, Anderson KS. Illuminating the molecular mechanisms of tyrosine kinase inhibitor resistance for the FGFR1 gatekeeper mutation: the Achilles' heel of targeted therapy. ACS Chem Biol. 2015;10(5):1319-29.

30. Ryan MR, SohI CD, Luo B, Anderson KS. The FGFR1 V561M gatekeeper mutation drives AZD4547 resistance through STAT3 activation and EMT. Mol Cancer Res. 2019;17(2):532-43.

31. Liang D, Chen Q, Guo Y, Zhang T, Guo W. Insight into resistance mechanisms of AZD4547 and E3810 to FGFR1 gatekeeper mutation via theoretical study. Drug Des Dev Therapy. 2017;11:451-61.

32. Bunney T, Wan S, Thiyagarajan N, Sutto L, Williams S, Ashford P, et al. The effect of mutations on drug sensitivity and kinase activity of fibroblast growth factor receptors: a combined experimental and theoretical study. EBioMedicine. 2015;2(3):194-204.
33. Cowell JK Qin H, Hu T, Wu O Bhole A, Ren M. Mutation in the FGFR1 tyrosine kinase domain or inactivation of PTEN is associated with acquired resistance to FGFR inhibitors in FGFR1-driven leukemia/lymphomas. Int J Cancer. 2017;141(9):1822-9.

34. Chell V, Balmanno K, Little AS, Wilson M, Andrews S, Blockley L, et al. Tumour cell responses to new fibroblast growth factor receptor tyrosine kinase inhibitors and identification of a gatekeeper mutation in FGFR3 as a mechanism of acquired resistance. Oncogene. 2013:32(25):3059-70.

35. Goyal L, Saha SK, Liu LY, Siravegna G, Leshchiner I, Ahronian LG, et al. Polyclonal secondary FGFR2 mutations drive acquired resistance to FGFR inhibition in patients with FGFR2 fusion-positive cholangiocarcinoma. Cancer Discov. 2017;7(3):252-63.

36. Tucker JA, Klein T, Breed J, Breeze AL, Overman R, Phillips C, et al. Structural insights into FGFR kinase isoform selectivity: diverse binding modes of AZD4547 and ponatinib in complex with FGFR1 and FGFR4. Structure. 2014;22(12):1764-74.

37. Goyal L, Shi L, Liu LY, Fece de la Cruz F, Lennerz JK, Raghavan S, et al. TAS-120 overcomes resistance to ATP-competitive FGFR inhibitors in patients with fGFR2 fusion-positive intrahepatic cholangiocarcinoma. Cancer Discov. 2019;9(8):1064-79.

38. Nakanishi Y, Akiyama N, Tsukaguchi T, Fujii T, Sakata K, Sase H, et al. The fibroblast growth factor receptor genetic status as a potential predictor of the sensitivity to $\mathrm{CH} 5183284$ /Debio 1347, a novel selective FGFR inhibitor. Mol Cancer Ther. 2014;13(11):2547-58.

39. Moss TJ, Ahnert JR, Oakley HD, Kahle M, Karp DD, Pant S, et al. Baseline cfDNA characteristics and evolution of cfDNA profile during treatment with selective FGFR inhibitor TAS-120. J Clin Oncol. 2019;37(15):258-9.

40. Hatlen MA, Schmidt-Kittler O, Sherwin CA, Rozsahegyi E, Rubin N, Sheets MP, et al. Acquired on-target clinical resistance validates FGFR4 as a driver of hepatocellular carcinoma. Cancer Discov. 2019;9(12):1686-95.

41. Shukla N, Ameur N, Yilmaz I, Nafa K, Lau C, Marchetti A, et al. Oncogene mutation profiling of pediatric solid tumors reveals significant subsets of embryonal rhabdomyosarcoma and neuroblastoma with mutated genes in growth signaling pathways. Clin Cancer Res. 2012;18(3):748-57.

42. Ang D, Ballard M, Beadling C, Warrick A, Schilling A, O'Gara R, et al Novel mutations in neuroendocrine carcinoma of the breast: possible therapeutic targets. Appl Immunohistochem Mol Morphol AIMM. 2015;23(2):97-103.

43. Huang Z, Tan L, Wang H, Liu Y, Blais S, Deng J, et al. DFG-out mode of inhibition by an irreversible type-1 inhibitor capable of overcoming gate-keeper mutations in FGF receptors. ACS Chem Biol. 2015;10(1):299-309

44. Wu D, Guo M, Min X, Dai S, Li M, Tan S, et al. LY2874455 potently inhibits FGFR gatekeeper mutants and overcomes mutation-based resistance. Chem Commun (Camb). 2018;54(85):12089-92.

45. Wu D, Guo M, Philips M, Qu L, Jiang L, Li J, et al. Crystal structure of the FGFR4/LY2874455 complex reveals insights into the pan-FGFR selectivity of LY2874455. PLOS ONE. 2016;11(9):e0162491.

46. Michael M, Bang Y, Park Y, Kang Y, Kim T, Hamid O, et al. A phase 1 study of LY2874455, an oral selective pan-FGFR inhibitor, in patients with advanced cancer. Target Oncol. 2017;12(4):463-74.

47. Tan F, Putoczki T, Stylli S, Luwor R. Ponatinib: a novel multi-tyrosine kinase inhibitor against human malignancies. OncoTargets Therapy. 2019:12:635-45.

48. Tan L, Wang J, Tanizaki J, Huang Z, Aref AR, Rusan M, et al. Development of covalent inhibitors that can overcome resistance to first-generation FGFR kinase inhibitors. Proc Natl Acad Sci USA. 2014;111(45):E4869-4877

49. Zhou Z, Chen X, Fu Y, Zhang Y, Dai S, Li J, et al. Characterization of FGF401 as a reversible covalent inhibitor of fibroblast growth factor receptor 4. Chem Commun (Camb). 2019;55(42):5890-3.

50. Weiss A, Adler F, Buhles A, Stamm C, Fairhurst R, Kiffe M, et al. FGF401, a first-in-class highly selective and potent FGFR4 inhibitor for the treatment of FGF19-driven hepatocellular cancer. Mol Cancer Ther. 2019;18(12):2194-206.

51. Rezende Miranda R, Fu Y, Chen X, Perino J, Cao P, Carpten J, et al. Development of a potent and specific FGFR4 inhibitor for the treatment of hepatocellular carcinoma. J Med Chem. 2020:63:11484-97. 
52. Lu X, Chen H, Patterson A, Smaill J, Ding K. Fibroblast growth factor receptor 4 (FGFR4) selective inhibitors as hepatocellular carcinoma therapy: advances and prospects. J Med Chem. 2019;62(6):2905-15.

53. Mo C, Zhang Z, Guise C, Li X, Luo J, Tu Z, et al. 2-Aminopyrimidine derivatives as new selective fibroblast growth factor receptor 4 (FGFR4) inhibitors. ACS Med Chem Lett. 2017;8(5):543-8.

54. Settembre C, Fraldi A, Medina DL, Ballabio A. Signals from the lysosome: a control centre for cellular clearance and energy metabolism. Nat Rev Mol Cell Biol. 2013;14(5):283-96.

55. Zhitomirsky B, Assaraf YG. Lysosomal sequestration of hydrophobic weak base chemotherapeutics triggers lysosomal biogenesis and lysosome-dependent cancer multidrug resistance. Oncotarget. 2015:6(2):1143-56.

56. Zhitomirsky B, Assaraf YG. Lysosomes as mediators of drug resistance in cancer. Drug Resist Updat. 2016;24:23-33.

57. Kazmi F, Hensley T, Pope C, Funk RS, Loewen GJ, Buckley DB, et al. Lysosomal sequestration (trapping) of lipophilic amine (cationic amphiphilic) drugs in immortalized human hepatocytes (Fa2N-4 cells). Drug Metab Dispos. 2013;41(4):897-905.

58. Englinger B, Kallus S, Senkiv J, Laemmerer A, Moser P, Gabler L, et al. Lysosomal sequestration impairs the activity of the preclinical FGFR inhibitor PD173074. Cells. 2018;7(12):259.

59. Englinger B, Kallus S, Senkiv J, Heilos D, Gabler L, van Schoonhoven $S$, et al. Intrinsic fluorescence of the clinically approved multikinase inhibitor nintedanib reveals lysosomal sequestration as resistance mechanism in FGFR-driven lung cancer. J Exp Clin Cancer Res. 2017:36(1):122.

60. Piao S, Amaravadi RK. Targeting the lysosome in cancer. Ann NY Acad Sci. 2016:1371(1):45-54

61. Gotink KJ, Rovithi M, de Haas RR, Honeywell RJ, Dekker H, Poel D, et al. Cross-resistance to clinically used tyrosine kinase inhibitors sunitinib, sorafenib and pazopanib. Cell Oncol (Dordr). 2015:38(2):119-29.

62. Chen C, Hsieh T, Lin Y, Liu Y, Liou J, Yen Y. Targeting autophagy by MPTOL145, a highly potent PIK3C3 inhibitor, provides synergistic interaction to targeted or chemotherapeutic agents in cancer cells. Cancers. 2019;11(9):1345.

63. Peng R, Chen Y, Wei L, Li G, Feng D, Liu S, et al. Resistance to FGFR1-targeted therapy leads to autophagy via TAK1/AMPK activation in gastric cancer. Gastric Cancer. 2020;23(6):988-1002.

64. Yamagishi T, Sahni S, Sharp DM, Arvind A, Jansson PJ, Richardson DR. P-glycoprotein mediates drug resistance via a novel mechanism involving lysosomal sequestration. J Biol Chem. 2013;288(44):31761-71.

65. Chapuy B, Panse M, Radunski U, Koch R, Wenzel D, Inagaki N, et al. $A B C$ transporter $A 3$ facilitates lysosomal sequestration of imatinib and modulates susceptibility of chronic myeloid leukemia cell lines to this drug. Haematologica. 2009;94(11):1528-36.

66. de Klerk DJ, Honeywell RJ, Jansen G, Peters GJ. Transporter and Iysosomal mediated (multi)drug resistance to tyrosine kinase inhibitors and potential strategies to overcome resistance. Cancers (Basel) 2018;10(12):503.

67. Martina JA, Chen Y, Gucek M, Puertollano R. MTORC1 functions as a transcriptional regulator of autophagy by preventing nuclear transport of TFEB. Autophagy. 2012;8(6):903-14.

68. Medina DL, Di Paola S, Peluso I, Armani A, De Stefani D, Venditti R, et al. Lysosomal calcium signalling regulates autophagy through calcineurin and TFEB. Nat Cell Biol. 2015;17(3):288-99.

69. Zhitomirsky B, Yunaev A, Kreiserman R, Kaplan A, Stark M, Assaraf YG. Lysosomotropic drugs activate TFEB via lysosomal membrane fluidization and consequent inhibition of mTORC1 activity. Cell Death Dis. 2018;9(12):1191.

70. Da Silva CG, Peters GJ, Ossendorp F, Cruz L. The potential of multicompound nanoparticles to bypass drug resistance in cancer. Cancer Chemother Pharmacol. 2017:80(5):881-94

71. Zhitomirsky B, Assaraf YG. The role of cytoplasmic-to-lysosomal pH gradient in hydrophobic weak base drug sequestration in lysosomes. Cancer Cell Microenviron. 2015;2:e807.

72. Adar Y, Stark M, Bram EE, Nowak-Sliwinska P, van den Bergh H, Szewczyk $G$, et al. Imidazoacridinone-dependent lysosomal photodestruction: a pharmacological Trojan horse approach to eradicate multidrug-resistant cancers. Cell Death Dis. 2012;3(4):e293.
73. Englinger B, Lötsch D, Pirker C, Mohr T, van Schoonhoven S, Boidol B, et al. Acquired nintedanib resistance in FGFR1-driven small cell lung cancer: role of endothelin-A receptor-activated $A B C B 1$ expression. Oncotarget. 2016;7(31):50161-79.

74. Ozvegy-Laczka C, Cserepes J, Elkind NB, Sarkadi B. Tyrosine kinase inhibitor resistance in cancer: role of $A B C$ multidrug transporters. Drug Resist Updat. 2005;8(1-2):15-26.

75. Krchniakova M, Skoda J, Neradil J, Chlapek P, Veselska R. Repurposing tyrosine kinase inhibitors to overcome multidrug resistance in cancer: a focus on transporters and lysosomal sequestration. Int J Mol Sci. 2020;21(9):3157.

76. Feng $W$, Zhang $M$, Wu Z, Wang J, Dong $X$, Yang Y, et al. Erdafitinib antagonizes $A B C B 1$-mediated multidrug resistance in cancer cells. Front Oncol. 2020;10:955.

77. Wu C, Hung T, Hsiao S, Huang Y, Hung L, Yu Y, et al. Erdafitinib resensitizes $A B C B 1$-overexpressing multidrug-resistant cancer cells to cytotoxic anticancer drugs. Cancers. 2020;12(6):1366.

78. Zhou Y, Wu C, Lu G, Hu Z, Chen Q, Du X. FGF/FGFR signaling pathway involved resistance in various cancer types. J Cancer. 2020;1 1(8):2000-7.

79. Datta J, Damodaran S, Parks H, Ocrainiciuc C, Miya J, Yu L, et al. Akt activation mediates acquired resistance to fibroblast growth factor receptor inhibitor BGJ398. Mol Cancer Ther. 2017;16(4):614-24.

80. Fearon AE, Carter EP, Clayton NS, Wilkes EH, Baker AM, Kapitonova E, et al. PHLDA1 mediates drug resistance in receptor tyrosine kinasedriven cancer. Cell Rep. 2018;22(9):2469-81.

81. Oda K, Stokoe D, Taketani Y, McCormick F. High frequency of coexistent mutations of PIK3CA and PTEN genes in endometrial carcinoma. Cancer Res. 2005;65(23):10669-73.

82. Byron SA, Gartside MG, Wellens CL, Mallon MA, Keenan JB, Powell MA, et al. Inhibition of activated fibroblast growth factor receptor 2 in endometrial cancer cells induces cell death despite PTEN abrogation. Cancer Res. 2008;68(17):6902-7.

83. Gozgit JM, Squillace RM, Wongchenko MJ, Miller D, Wardwell S, Mohemmad $\mathrm{Q}$, et al. Combined targeting of FGFR2 and mTOR by ponatinib and ridaforolimus results in synergistic antitumor activity in FGFR2 mutant endometrial cancer models. Cancer Chemother Pharmacol. 2013;71(5):1315-23.

84. Lau WM, Teng E, Huang KK, Tan JW, Das K, Zang Z, et al. Acquired resistance to FGFR inhibitor in diffuse-type gastric cancer through an AKTindependent PKC-mediated phosphorylation of GSK3 $\beta$. Mol Cancer Ther. 2018;17(1):232-42.

85. Bockorny B, Rusan M, Chen W, Liao RG, Li Y, Piccioni F, et al. RAS-MAPK reactivation facilitates acquired resistance in FGFR1-amplified lung cancer and underlies a rationale for upfront FGFR-MEK blockade. Mol Cancer Ther. 2018;17(7):1526-39.

86. Kas SM, de Ruiter JR, Schipper K, Schut E, Bombardelli L, Wientjens E, et al. Transcriptomics and transposon mutagenesis identify multiple mechanisms of resistance to the FGFR inhibitor AZD4547. Cancer Res. 2018;78(19):5668-79.

87. Hayashi T, Desmeules P, Smith R, Drilon A, Somwar R, Ladanyi M. RASA1 and are preferentially co-mutated and define a distinct genetic subset of smoking-associated non-small cell lung carcinomas sensitive to MEK inhibition. Clinical Cancer Res. 2018;24(6):1436-47.

88. Fumarola C, Bozza N, Castelli R, Ferlenghi F, Marseglia G, Lodola A, et al. Expanding the arsenal of FGFR inhibitors: a novel chloroacetamide derivative as a new irreversible agent with anti-proliferative activity against FGFR1-amplified lung cancer cell lines. Front Oncol. 2019;9:179.

89. Malchers F, Ercanoglu M, Schutte D, Castiglione R, Tischler V, Michels S, et al. Mechanisms of primary drug resistance in FGFR1-amplified lung cancer. Clin Cancer Res. 2017;23(18):5527-36.

90. Kitai H, Ebi H. Key roles of EMT for adaptive resistance to MEK inhibitor in KRAS mutant lung cancer. Small GTPases. 2017;8(3):172-6.

91. Wang L, Šuštić T, LeitedeOliveira R, Lieftink C, Halonen P, van de Ven $M$, et al. A functional genetic screen identifies the phosphoinositide 3-kinase pathway as a determinant of resistance to fibroblast growth factor receptor inhibitors in FGFR mutant urothelial cell carcinoma. Eur Urol. 2017;71(6):858-62.

92. Wang J, Mikse O, Liao RG, Li Y, Tan L, Janne PA, et al. Ligand-associated ERBB2/3 activation confers acquired resistance to FGFR inhibition in FGFR3-dependent cancer cells. Oncogene. 2015;34(17):2167-77. 
93. Singleton KR, Kim J, Hinz TK, Marek LA, Casás-Selves M, Hatheway $C$, et al. A receptor tyrosine kinase network composed of fibroblast growth factor receptors, epidermal growth factor receptor, v-erb-b2 erythroblastic leukemia viral oncogene homolog 2, and hepatocyte growth factor receptor drives growth and survival of head and neck squamous carcinoma cell lines. Mol Pharmacol. 2013;83(4):882-93.

94. Kim SM, Kim H, Yun MR, Kang HN, Pyo KH, Park HJ, et al. Activation of the Met kinase confers acquired drug resistance in FGFR-targeted lung cancer therapy. Oncogenesis. 2016:5(7):e241.

95. Herrera-Abreu MT, Pearson A, Campbell J, Shnyder SD, Knowles MA, Ashworth A, et al. Parallel RNA interference screens identify EGFR activation as an escape mechanism in FGFR3-mutant cancer. Cancer Discov. 2013;3(9):1058-71.

96. Lee SY, Na YJ, Jeong YA, Kim JL, Oh SC, Lee DH. Upregulation of EphB3 in gastric cancer with acquired resistance to a FGFR inhibitor. Int J Biochem Cell Biol. 2018;102:128-37.

97. Grygielewicz P, Dymek B, Bujak A, Gunerka P, Stanczak A, LamparskaPrzybysz $M$, et al. Epithelial-mesenchymal transition confers resistance to selective FGFR inhibitors in SNU-16 gastric cancer cells. Gastric Cancer. 2016;19(1):53-62.

98. Bauer S, Duensing A, Demetri G, Fletcher J. KIT oncogenic signaling mechanisms in imatinib-resistant gastrointestinal stromal tumor: PI3kinase/AKT is a crucial survival pathway. Oncogene. 2007;26(54):7560-8.

99. Maroun CR, Rowlands T. The Met receptor tyrosine kinase: a key player in oncogenesis and drug resistance. Pharmacol Ther. 2014;142(3):316-38.

100. Wang Q, Yang S, Wang K, Sun S. MET inhibitors for targeted therapy of EGFR TKI-resistant lung cancer. J Hematol Oncol. 2019;12(1):63.

101. Harbinski F, Craig VJ, Sanghavi S, Jeffery D, Liu L, Sheppard KA, et al. Rescue screens with secreted proteins reveal compensatory potential of receptor tyrosine kinases in driving cancer growth. Cancer Discov. 2012;2(10):948-59.

102. Terai H, Soejima K, Yasuda H, Nakayama S, Hamamoto J, Arai D, et al. Activation of the FGF2-FGFR1 autocrine pathway: a novel mechanism of acquired resistance to gefitinib in NSCLC. Mol Cancer Res. 2013;11(7):759-67.

103. Javidi-Sharifi N, Traer E, Martinez J, Gupta A, Taguchi T, Dunlap J, et al. Crosstalk between KIT and FGFR3 promotes gastrointestinal stromal tumor cell growth and drug resistance. Cancer Res. 2015;75(5):880-91.

104. Rausch M, Weiss A, Achkhanian J, Rotari A, Nowak-Sliwinska P. Identification of low-dose multidrug combinations for sunitinib-naive and pretreated renal cell carcinoma. Br J Cancer. 2020;123(4):556-67.

105. Cai W, Song B, Ai H. Combined inhibition of FGFR and mTOR pathways is effective in suppressing ovarian cancer. Am J Transl Res. 2019;11(3):1616-25

106. Lamberti D, Cristinziano G, Porru M, Leonetti C, Egan JB, Shi CX, et al. HSP90 inhibition drives degradation of FGFR2 fusion proteins: implications for treatment of cholangiocarcinoma. Hepatology. 2019;69(1):131-42.

107. Katoh M. Fibroblast growth factor receptors as treatment targets in clinical oncology. Nat Rev Clin Oncol. 2019;16(2):105-22.

108. Qin Q, Patel V, Galsky M. Urothelial carcinoma: the development of FGFR inhibitors in combination with immune checkpoint inhibitors. Expert Rev Anticancer Therapy. 2020;20(6):503-12.

109. Mollica V, Rizzo A, Montironi R, Cheng L, Giunchi F, Schiavina R, et al. Current strategies and novel therapeutic approaches for metastatic urothelial carcinoma. Cancers. 2020;12(6):1449.

110. Shimizu T, Tolcher AW, Papadopoulos KP, Beeram M, Rasco DW, Smith $\mathrm{LS}$, et al. The clinical effect of the dual-targeting strategy involving PI3K AKT/mTOR and RAS/MEK/ERK pathways in patients with advanced cancer. Clin Cancer Res. 2012;18(8):2316-25.

111. Peng $X$, Hou P, Chen Y, Dai Y, Ji Y, Shen Y, et al. Preclinical evaluation of 3D185, a novel potent inhibitor of FGFR1/2/3 and CSF-1R, in
FGFR-dependent and macrophage-dominant cancer models. J Exp Clin Cancer Res. 2019;38(1):372.

112. Chen $\mathrm{CH}$, Changou CA, Hsieh TH, Lee YC, Chu CY, Hsu KC, et al. Dual inhibition of PIK3C3 and FGFR as a new therapeutic approach to treat bladder cancer. Clin Cancer Res. 2018:24(5):1176-89.

113. Schram AM, Chang MT, Jonsson P, Drilon A. Fusions in solid tumours: diagnostic strategies, targeted therapy, and acquired resistance. Nat Rev Clin Oncol. 2017;14(12):735-48.

114. Savage N, George TI, Gotlib J. Myeloid neoplasms associated with eosinophilia and rearrangement of PDGFRA, PDGFRB, and FGFR1: a review. Int J Lab Hematol. 2013;35(5):491-500.

115. Kim SY, Ahn T, Bang H, Ham JS, Kim J, Kim ST, et al. Acquired resistance to LY2874455 in FGFR2-amplified gastric cancer through an emergence of novel FGFR2-ACSL5 fusion. Oncotarget. 2017;8(9):15014-22.

116. Osawa T, Muramatsu M, Wang F, Tsuchida R, Kodama T, Minami T, et al. Increased expression of histone demethylase JHDM1D under nutrient starvation suppresses tumor growth via down-regulating angiogenesis. Proc Natl Acad Sci USA. 2011;108(51):20725-9.

117. Garnett MJ, Rana S, Paterson H, Barford D, Marais R. Wild-type and mutant B-RAF activate C-RAF through distinct mechanisms involving heterodimerization. Mol Cell. 2005;20(6):963-9.

118. Sase H, Nakanishi Y, Aida S, Horiguchi-Takei K, Akiyama N, Fujii T, et al. Acquired JHDM1D-BRAF fusion confers resistance to FGFR inhibition in FGFR2-amplified gastric cancer. Mol Cancer Ther. 2018;17(10):2217-25.

119. Ware K, Hinz T, Kleczko E, Singleton K, Marek L, Helfrich B, et al. A mechanism of resistance to gefitinib mediated by cellular reprogramming and the acquisition of an FGF2-FGFR1 autocrine growth loop. Oncogenesis. 2013;2:e39.

120. Marek L, Ware K, Fritzsche A, Hercule P, Helton W, Smith J, et al. Fibroblast growth factor (FGF) and FGF receptor-mediated autocrine signaling in non-small-cell lung cancer cells. Mol Pharmacol. 2009;75(1):196-207

121. Coleman S, Chioni A, Ghallab M, Anderson R, Lemoine N, Kocher H, et al. Nuclear translocation of FGFR1 and FGF2 in pancreatic stellate cells facilitates pancreatic cancer cell invasion. EMBO Mol Med. 2014;6(4):467-81

122. Chang J, Liu X, Wang S, Zhang Z, Wu Z, Zhang X, et al. Prognostic value of FGFR gene amplification in patients with different types of cancer: a systematic review and meta-analysis. PLOS ONE. 2014;9(8):e105524.

123. Ghedini GC, Ronca R, Presta M, Giacomini A. Future applications of FGF/FGFR inhibitors in cancer. Expert Rev Anticancer Ther. 2018;18(9):861-72.

124. Kim Y, Kim Y, Lee S, Yang H, Kim S. Personalized prediction of acquired resistance to EGFR-targeted inhibitors using a pathway-based machine learning approach. Cancers. 2019;11(1):45.

125. Hauser K, Negron C, Albanese S, Ray S, Steinbrecher T, Abel R, et al. Predicting resistance of clinical Abl mutations to targeted kinase inhibitors using alchemical free-energy calculations. Commun Biol. 2018;1:70.

126. Aldeghi M, Gapsys V, de Groot B. Predicting kinase inhibitor resistance: physics-based and data-driven approaches. ACS Cent Sci. 2019;5(8):1468-74.

127. Chae Y, Ranganath K, Hammerman P, Vaklavas C, Mohindra N, Kalyan A, et al. Inhibition of the fibroblast growth factor receptor (FGFR) pathway: the current landscape and barriers to clinical application. Oncotarget. 2017:8(9):16052-74.

128. Cheng F, Su L, Qian C. Circulating tumor DNA: a promising biomarker in the liquid biopsy of cancer. Oncotarget. 2016;7(30):48832-41.

\section{Publisher's Note}

Springer Nature remains neutral with regard to jurisdictional claims in published maps and institutional affiliations. 